\title{
Relationships of Exclusion and Cohesion with Health: The Case of Bangladesh
}

\author{
Heidi Bart Johnston \\ Public Health Sciences Division, ICDDR,B, GPO Box I28, Dhaka 1000, Bangladesh
}

\begin{abstract}
The concept of social exclusion, applied widely in the European Union, has in recent years been gaining use in Bangladesh, mostly by international development agencies. Does this discourse of deprivation, developed in the welfare states of northern Europe, have salience in its application to deprivation in countries like Bangladesh where, for example, $31 \%$ of the rural population lives in chronic poverty? The concept of social exclusion has three principal components: a dynamic and relational perspective which requires the identification of who or what causes exclusion; an explicit recognition of multiple dimensions of deprivation; and a longitudinal perspective, recognizing that individuals and groups are dynamic intra- and intergenerationally. The Social Exclusion Knowledge Network of the World Health Organization Commission on Social Determinants of Health expanded the concept to include health status as a contributor to and an outcome of exclusion and to show that actors beyond the state or public sector can critically impact exclusionary processes. In the Bangladesh application, the relevance of the modified model was explored to find that while there are negative associations between social exclusion and health status, much stronger documentation is needed of the relationship. The modification of including multiple sectors, such as private enterprise and civil society, in addition to the state, as having potential to impact exclusionary processes is fundamental to the application of the social exclusion model in Bangladesh.
\end{abstract}

Key words: Health equity; Social determinants of health; Social exclusion; Bangladesh

\section{RELEVANCE OF SOCIAL EXCLUSION THEORY IN BANGLADESH}

The concept of social exclusion is a relatively new tool for analyzing social disparities in South Asia (1). The concept has its modern origins in France in the 1970s, referring to breakdowns of individuals from society and the state. The concept adapted as it was applied in a more individualistic England and the European Union where a concern with fundamental human rights prevails. In these adaptations, the relationships between the individual and the established welfare state remain fundamental (2). In the South Asian context, relationships between the individual and the state are far less central. Does the concept of social exclusion have sufficient resilience to maintain its value in such contexts?

Correspondence and reprint requests should be addressed to:

Dr. Heidi Johnston

Public Health Sciences Division

ICDDR,B

GPO Box 128

Dhaka 1000

Bangladesh

Email: heidibartjohnston@gmail.com
With the question of widespread applicability in mind, the Social Exclusion Knowledge Network of the World Health Organization Commission on Social Determinants of Health reviewed and adapted the social exclusion concept to enhance its applicability and analytical potential. This paper applies this modified social exclusion concept in an analysis of different policies and actions implemented in Bangladesh that are meant to or do enhance livelihoods. Drawing from these multiple analyses, this paper (a) assesses the applicability of the concept of social exclusion to the Bangladesh context, (b) questions the benefits of introducing a new concept for analyzing policies and actions meant to promote development, and (c) explores the documented relationships between increasing capabilities and resources (i.e. diminishing exclusion) and health status.

\section{Social exclusion: an evolving concept}

As applied in this paper, the fundamental characteristics of the social exclusion framework are three-fold. First, social exclusion is relational, recognizing an interplay between agency and structure (3), acknowledging that social relations are fixed in 
formal and informal political, economic, social and cultural institutions in society that are dynamic $(1,4)$. This dynamic and relational approach directs the analyst to investigate not only the excluded but also those who exclude and the processes of exclusion (5). The approach furthermore acknowledges the importance of agency-relating to participation, a critical and longstanding concept in development discourse. The conceptualization of interplay between agency and structure rather than state suggests that institutions of power and authority beyond the state influence position in society. This adaptation is essential for the social exclusion concept to have salience beyond the strong welfare states, such as those in northern Europe.

Second, social exclusion is multidimensional, acknowledging that forces that exclude people from full participation in society can be social, cultural, political, and economic. Beall and Piron describe economic exclusion as "exclusion from labor markets, employment, and enterprise opportunities and a wide range of livelihood strategies" (5); exclusion from social participation is described as "exclusion from access to infrastructure and services, social security and protection, public safety and social cohesion." Exclusion from political participation includes "restricted access to organization, decision-making, and the rights and responsibilities of citizenship." The processes or dynamics of social exclusion are power-based, operating through social relations and social, political, cultural and economic institutions (5). And third, social exclusion takes a longitudinal perspective, with an emphasis on transitions through the life course and intergenerational processes (6).

Is this representation of the essentials of the social exclusion concept transferable from its origins in northern Europe to countries with weak public welfare programmes? Previous scholarship on social exclusion in developing countries provides promising results. For example, in her analysis of progress towards the Millennium Development Goals (MDGs) in Asian countries, Kabeer reviewed existing evidence and demonstrated the applicability and advantages of a social exclusion framework to better understand the social dimensions of poverty and the processes associated with inequality (7). However, Kabeer failed to explicitly define social exclusion beyond a recognition of multiple and overlapping layers of deprivation. Likewise, Hobcraft notes that the concept of social exclusion is implicit in the MDGs, stating "while not generally couched in social exclusion terms, the major shifts in UN development thinking over the past decade or so, and much in research on chronic poverty, do resonate with the social exclusion approach as seen in the UK" (6). Elsewhere in the paper, Hobcraft writes: "The integrated treatment of multiple disadvantages-the 'more than poverty' element of social exclusion-is already a major element of the development agenda. The MDGs demonstrate a recognition that a whole package of areas of progress is required and that poverty, although of crucial importance, cannot be tackled in isolation" (6).

Rahman and Razzaque showed that poverty-alleviation programmes in Bangladesh have long aimed at addressing the multiple disadvantages that face the poor (8). Programmes, such as microcredit, promote social, cultural and economic capabilities to facilitate the disadvantaged to attain sustainable livelihoods (8). The modern strategy of microcredit emerged in the 1970s, almost simultaneously to the modern concept of social exclusion, though in very different contexts. Like the social exclusion analytical framework, the microcredit strategy addresses multiple sources of deprivation and recognizes the agency of individuals to alter their position in society. Microcredit and other development strategies implemented in Bangladesh are very much in line with the concept of social exclusion presented in this paper. Thus, while the concept of social exclusion resonates in Bangladesh, one should question whether it has value over existing analytical frameworks as a tool for designing and critically analyzing social development efforts.

Following this line of thinking, Saith maintains, "most features of the 'social exclusion' concept (attention to multiple dimensions, social relationships, assessing the poverty of individuals relative to others in society, and concern with the dynamics of poverty) are shared by concepts implemented in developing countries" (9). Concepts, such as "basic capabilities', risk aversion, vulnerability, and sustainable livelihoods are in the discourse. Still, Saith suggests, "these existing frameworks could benefit by taking from social exclusion its emphasis on investigating the processes that lead to poverty." Saith argues that it would be "sufficient to incorporate an emphasis on looking at processes within re-existing frameworks in developing countries, rather than re-doing poverty analyses under the rubric of 'social exclusion" (9).

While the multidimensionality of deprivation and the importance of individual agency are certainly 
important elements of many development programmes, one can argue that these aspects are generally implicitly recognized and as such are too often applied as convenience allows. The threepronged approach to social exclusion has benefit over current development discourse not only because it emphasizes the dynamics between individual capability and societal structures, underscoring the important question of who or what is causing or contributing to the exclusion but also because it explicitly identifies key dimensions of deprivation and emphasizes longitudinal processes, thus adding breadth and depth to deprivation analysis.

Health is an essential component of individual and societal livelihood. A growing body of literature demonstrates the negative two-way relationship between deprivation and health. However, fewer studies have explored relationships between the structural factors that contribute to deprivation and health status. Health is not a dimension typically included in social exclusion analysis.

Factors that contribute to different levels of deprivation are not straightforward, are typically multiple, and can include health status and access to social, cultural, political and economic capabilities and resources. Health has a critical role for development in low-income countries like Bangladesh: better health translates into greater and more equitably-distributed wealth by building human and social capital and increasing productivity (10). Likewise, cost of healthcare can be a cause of poverty through loss of income, catastrophic health expenditure, and potentially irreversible crisis-coping mechanisms that involve asset and savings depletion $(11,12)$. The income erosion effect of ill-health for the poor households, especially the bottom 15$20 \%$, is also well-documented in Bangladesh (13).

The social exclusion and health framework of the Social Exclusion Knowledge Network does include health status as a prominent outcome of and contributor to exclusion (Fig.). The model also shows the importance of a number of actors (state, religion, civil society, labour movements, international agencies, private enterprises, households, individuals, etc.) in contributing to individuals' positions on the continua of social, economic, political and cultural capabilities and resources. Differential capabilities and resources contribute to health status. Health inequities, in turn, influence one's position in society and affect individual capabilities and resources. Multiple dimensions of inclusion or exclusion have impact to greater or lesser degrees, depending on the individual or group. The task implicit in the model is to identify who or what in society contributes to exclusion or inclusion, shifting the analytical focus from the excluded to the actors and processes that impact exclusion. This analytical shift could impact the understanding of exclusion and the processes to ameliorate exclusion. Recognizing who or what in society contributes to exclusion takes us a step closer to reducing exclusion and its negative impact on health (14). It is this model, presented by the Social Exclusion Knowledge Network of the World Health Organization Commission on Social Determinants of Health, that provides the theoretical framework for the analysis presented in this paper.

\section{SOCIAL EXCLUSION AND HEALTH POLICY ACTION APPRAISALS}

This paper is an analysis of select policies and actions implemented in Bangladesh that have the potential to shift the relationship between societal structures and individuals to reduce deprivation. Associations between the policies or actions and shifts in exclusion and health status are explored to the extent that available documentation has allowed. The topics of the case studies conducted as background papers for this analysis were selected purposively, to represent diverse policies and actions addressing multiple capabilities and resources and to represent policies and actions implemented by a range of actors. The policies and actions included are also believed to have relevance in Bangladesh and internationally for addressing exclusion.

Each description of a policy or action includes the implementing agency, the action, links to social exclusion, evidence of impact, particularly on health, if data are available, and enablers and barriers to success. The presentation of policies and actions is organized according to category of implementing agency: state, not-for-profit non-governmental organizations (NGOs), and private for-profit organizations. Examples of multisectoral action are also included; for example, NGOs working with private sector and the state working with communities.

\section{State action}

In Bangladesh, a patchwork of social protection programmes provide benefit to an estimated 15 million people. Coverage of the social protection programmes has decreased in recent years, from the equivalent of $1 \%$ of GDP in the late 1990 s to less than half of $1 \%$ of GDP in 2004, or less than $5 \%$ of public expenditure (15). The Female Second- 


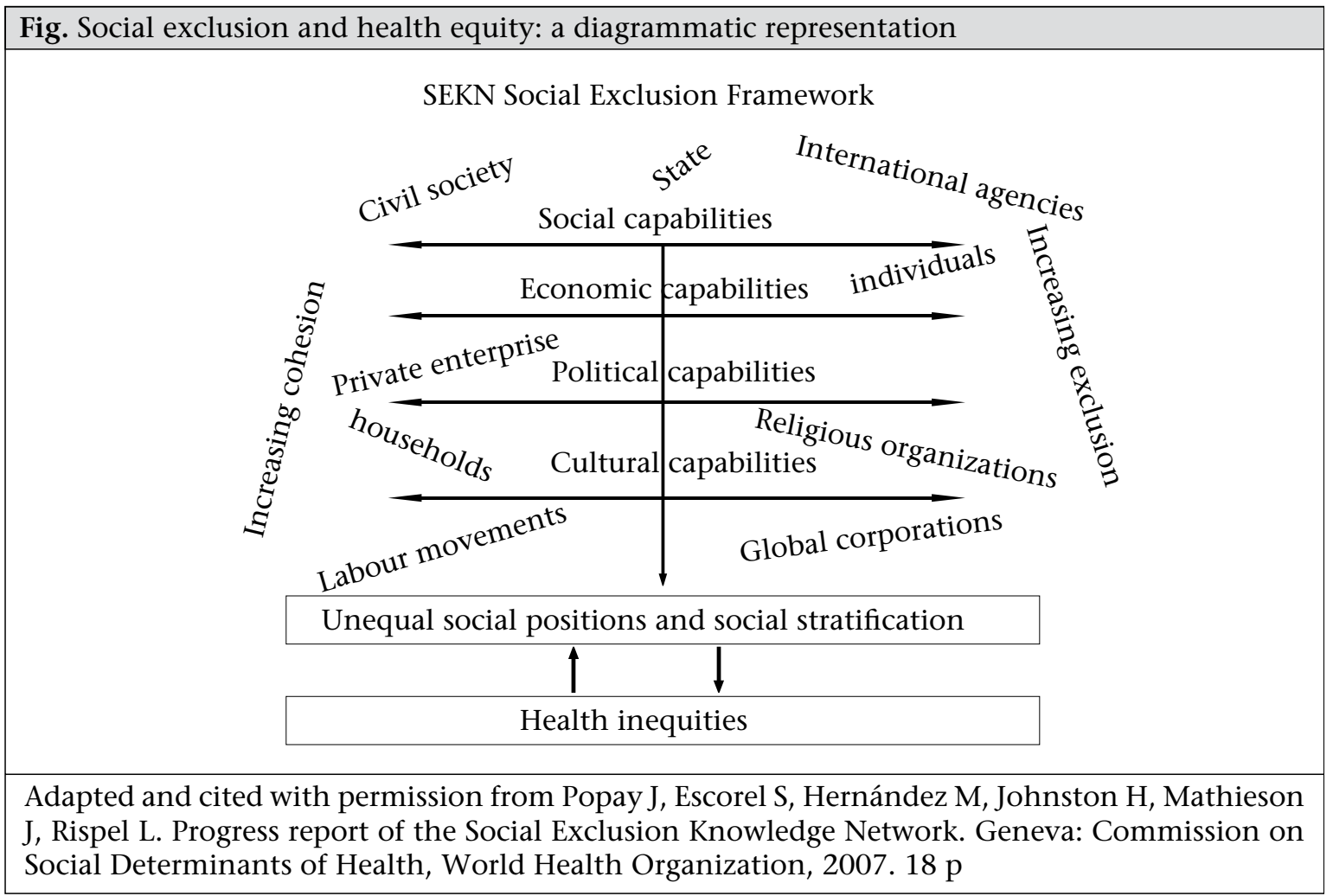

ary School Stipend Project (FSP) is an example of a public sector social protection programme.

\section{Female Secondary School Stipend Project (I 6)}

Education is a basic right provided by the state. Higher levels of education are linked to greater social cohesion and to more informed decision-making and actions regarding health. The FSP is a conditional cash-transfer programme originally implemented with the intention of increasing enrollment of girls in secondary schools anticipating higher levels of education for girls as an interim step leading to the individual and societal health benefit of delayed marriage and childbearing. The FSP provides parents of female students in secondary schools a portion of tuition, school fees, and monthly stipends up to class 10 conditional upon their daughter attending a recognized institution, remaining unmarried, having $75 \%$ attendance, and securing $45 \%$ marks on annual examination. The project is not targeted to a particular group, i.e. provides benefits regardless of financial standing. The FSP was piloted in 1977 and, by 1994, had been scaled up throughout rural Bangladesh.

The FSP has not been well-monitored and was implemented alongside several similarly-oriented programmes; so, its impact is difficult to measure. However, females as a percentage of secondary school enrollees increased from 33\% in 1991 to $52 \%$ in 2005 , and it is very likely that the FSP played a key role in the increased levels of education among girls. The FSP has not had its intended impact on delaying marriage and fertility-the trend of early marriage in Bangladesh remains unchanged (17). Has the FSP enhanced capabilities of girls? As an indicator, data from 2005 suggest that only 35\% of students enrolling in secondary schools passed the secondary school examination, which implies that, in its current form, secondary school has limited transformative capacity; however, a slightly higher proportion of girls than boys pass, suggesting that the value of education for girls is being realized.

By providing a stipend insufficient to cover the complete costs of education and that often arrives late, the FSP likely serves as an incentive for families with sufficient financial resources to send their daughters to secondary schools. The FSP may have less impact on families with fewer financial resources. (Indeed, two of the top three reasons for dropping out of school are finance-based). As the FSP incentives generally are not accessed by those who cannot afford to pay a portion of the educational cost of their daughters, the FSP has the potential to exclude the poor and ultra-poor and increase the gap in access to education and other societal resources, contributing to increased levels of social exclusion. 
In general, cash transfers in Bangladesh have been found to be inefficient and subject to leakage. There are problems with inappropriate targeting, high administrative costs, and poor programme monitoring. Furthermore, the public is not well-informed about the programmes, limiting their participation, support, and civil society monitoring (18).

In Bangladesh, the public sector very often works through NGOs, many of which have established strong relationships with the communities they serve. Several examples of public sector and NGO partnership are presented below.

NGO or not-for-profit action

NGOs play important and diverse roles in promoting livelihood in Bangladesh. Examples are given of NGOs developing and implementing their own development strategies; of developing innovations and implementing these with government support, community support, and with the support of the private for-profit sector.

\section{Microcredit (| 9)}

In the 'group borrowing' model of microcreditbased income-earning interventions, small amounts of credit are provided to small groups of people. Many microcredit institutions, including the largest two-Grameen Bank and BRAC_-use the regular group loan transaction meetings as capability-enhancing forums focusing on human capital development, promoting gender equity, building legal awareness, and health interventions. Twenty million people actively participate in microcredit in Bangladesh: 87\% of participants are women, and $78 \%$ earn less than US $\$ 1$ per day. Women are the targeted beneficiaries of microcredit as evidence shows that women are generally more reliable debtors than men and are more likely to spend earned income to benefit the household on items, such as food, education, and assets (20).

In a context of purdah [practice of keeping females secluded from all men except those related by blood] and rural poverty, microcredit-based incomeearning interventions provide women the access to and support for income-generating activities despite their restricted mobility and minimal access to financial resources and assets. This is critical as employment opportunities in the agricultural sector are declining, and long commutes to formalsector work opportunities are prohibited for many women.

Microcredit can be an effective strategy for building social and economic capital $(21,22)$. Evidence suggests strong and positive impacts on health although causality is difficult to determine. Participation in microcredit programmes is associated with improved knowledge and use of qualified healthcare providers $(23,24)$, smaller desired family size and higher rates of modern contraceptive use $(25,26)$, and better nutritional status, particularly among the girl children of microcredit borrowers (21).

Some keys to the success of group-based microcredit are the use of social rather than physical collateral, encouraging women to develop broader social networks. The weekly meetings of the members provide an opportunity to promote messages on health and rights, and skills building. While microcredit has provided a path to greater economic, social, and even political participation and is altering restrictive cultural norms of purdah, generally the microcredit enterprises work at small scale, and earnings are meagre.

Some features of microcredit have been found to increase the poverty and vulnerability of the extreme poor and those with no entrepreneurial skills. Microcredit is not beneficial for those who do not work well with the strict discipline of microcredit institutions, who fear monetary transactions, and who have no financial safety-net (27). Furthermore, participation in microcredit programmes can put the extreme poor into further poverty and exclusion. BRAC's Targeting the Ultra-poor Programme, discussed below, is an intervention targeted at those who are too poor to benefit from microcredit.

\section{Challenging the frontiers of poverty reduction/ targeting the ultra-poor (28)}

In Bangladesh, the official poverty-line corresponds to $2,112 \mathrm{kcal}$ per person per day (29). The proportion of population falling between upper (corresponding to the consumption of 2,112 kcal per person per day) and lower (corresponding to the consumption of $1,805 \mathrm{kcal}$ per person per day) poverty-line are termed as 'moderate poor' while those falling below the lower poverty-line are variously termed as 'extreme poor', 'poorest of the poor,' or 'ultra-poor' (30). These ultra-poor households have little or no asset base, are highly vulnerable to any shock, such as natural disaster, illnesses requiring inpatient or costly outpatient care, death, or disability of an income-earner, and mainly depend on wage-labour for survival. They comprise about 10\% of the population in rural Bangladesh (31).

BRAC developed an intervention recognizing and responding to the multiple layers of dep- 
rivation that exclude the ultra-poor: 'Challenging the Frontiers of Poverty Reduction/Targeting the Ultra-poor' (CFPR/TUP). CFPR/TUP, launched in 2002 , integrates components specifically designed to address sociocultural, political and economic exclusion, including income generation, skills training, a monthly stipend for subsistence (US\$ 0.17 per day), social development and mobilization of the local elite for support. A mid-term evaluation showed that the CFPR/TUP programme positively impacted livelihood, economic, social and health status to the extent that some households maintained asset growth after 'graduation' and joined a regular microcredit programme: $55 \%$ of the 5,000 poorest households from the poorest districts in the country gained sufficient resources to benefit from joining a microcredit programme; the percentage living on <US $\$ 1$ per day decreased from $89 \%$ to $59 \%$ during the first three years of the project, and improvements were observed in quantity and quality of dietary intake (32-33).

Despite successes associated with explicitly addressing multiple dimensions of exclusion, it is clear that some extreme poor have not yet been able to benefit from CFPR/TUP. Reasons for this need to be explored to facilitate further interventions.

\section{NGO-state partnerships}

Several examplesillustratethestrength ofmultisectoralapproaches. Therearemany examplesin Bangladesh of NGOs identifying community needs, showing leadership in developing innovations, and working with the public sector to scale up programmes. In this section, interventions of NGOs working with the public sector facilitating access to healthcare and safe water-supply and to generate civil society action to promote public sector accountability to the citizenry are described.

\section{Healthcare services: Urban Primary Health Care Project (34)}

As informal settlements, or slums, are considered 'illegal', populations who live in these areas often have no official addresses and are commonly denied basic rights and entitlements, including the right to access water, sanitation, education, and healthcare. A review of health services for people who live in informal settlements in Dhaka city found that only $7.3 \%$ have access to a public-health clinic. While the situation remains dismal for many urban poor residents who, at public-sector clinics, report being mistreated, waiting long hours, receiving poorquality care, and remaining uninformed of their rights $(35,36)$, there have also been some successful projects implemented to promote access to health services for the urban poor.

The Urban Primary Healthcare Project was first implemented in the four major metropolitan areas of Dhaka, Khulna, Chittagong, and Rajshahi. Through city corporation-NGO partnership agreements, first signed in May 2000, the Government contracted with NGOs to establish primary healthcare clinics in low-income areas of the four cities. Through these services, the poorest women and children living in informal settlements are offered affordable and accessible primary healthcare services of high quality. This population constitutes more than $75 \%$ of all project beneficiaries. In 2001, the coverage included 400,000 people in four city corporation areas. In December 2004, a project review showed that 5 million people were covered, the quality of services was very good, the services were user-friendly, patients received services for a subsidized rate, and the hardcore poor received services free of charge. The project has expanded to six city corporations and five municipalities (35). The Urban Primary Healthcare Project has decreased the spatial and economic exclusion of urban poor from healthcare services.

Safe water supply: Dushtha Shasthya Kendra and
Dhaka Water Supply and Sewerage Authority (34)

Dhaka's Water Supply and Sewerage Authority (WASA), the public-sector water-utility agency, has had a policy that they would not provide water services to households without a legal land-holding permit, which effectively excludes informal settlements from access to safe water-supply. To circumvent this obstacle, the NGO-Dushtha Shasthya Kendra (DSK: Vulnerable Poor Health Centre)—approached WASA in 1992 with a proposal to deliver water services to two informal settlements where residents accessed water from a pool of contaminated factory wastes (37). The DSK offered to act as the guarantor for the security deposit and the bill payments for the beneficiaries (35). After negotiations, WASA agreed to waive their policy and authorized two water points. The initial cost was Tk 70,000 (approximately US\$1,000).

The first water-point installation was not successful as the local informal power structure took control of the water-point and refused to pay the weekly installments. The DSK tried again, installing the second water-point in 1994. Prior to installation, two groups of elected Water Management Committees 
were formed-one comprised women, the other comprised men. The committees managed and maintained the water-point, paid bills to WASA, and made installment payments to the DSK. This second initiative was successful. Four years later, the DSK recovered the initial cost, WASA bills were being paid on time, and the community had a safe water-supply system.

The DSK model prompted the water authority to allow communities to apply for water connections on their own behalf without the need for a guarantor. Eighty-eight water-points have been established since 1996 in 70 informal settlement areas. The water authority is also cooperating in the replication of the project in 110 community-managed water systems benefiting around 60,000 people who live in informal settlements, with plans to expand the arrangement to one of the largest informal settlements in the city with over 250,000 inhabitants (35).

The success of the project shows the potential for residents of informal communities to be reliable clients, responsible, and willing to pay for services. The success draws on and further develops the capabilities of the residents, convincing the public and NGO sectors that the intervention could work in other areas. The residents have the intended benefits of a safe water-supply and the unintended benefits of generating cohesion (trust) with networks beyond the informal settlement setting.

NGO, public sector and civil society partnerships

Civil society action is promoted as a mechanism to mobilize government accountability and relevance in service provision. There is a strong need for action to adjust distribution of public-sector funds to the health sector in Bangladesh where the wealthiest $20 \%$ of the population receive over $26 \%$ of total financial subsidies provided by government health expenditure compared to the poorest 20\% of the population receiving 16\% (38). In addition, health service provision is plagued by negligence, unprofessional behaviour by service providers, poor maintenance of physical facilities, illegal userfees, leakages of resources, and long waiting-times. While there have been internal systems in place to ensure the quality of care and accountability, they have been largely non-functional (39). In the Bangladesh setting, there is a possibility that increased civil society action could contribute to re-aligning public healthcare service-delivery according to health rights and social welfare goals.
Stakeholder consultation committees for the Health and Population Sector Programme (40)

The five-year (1998-2003) Health and Population Sector Programme (HPSP) of the Government of Bangladesh highlighted the importance of stakeholder consultation and participation. The Ministry of Health and Family Welfare requested NGOs, with their strong networks at the community level, to establish stakeholder committees of local resident service-users to monitor the performance of public healthcare providers at the local level. A national stakeholder committee, nine upazila (a subdistrict with a population typically around 250,000) stakeholder committees, and 16 union (the administrative unit below the upazila) stakeholder committees were formed. An NGO_Nijera Kori-with a long history of social mobilization, was asked to arrange local meetings in different parts of the country to let villagers provide input into how the stakeholder committees might work. Four NGOs-Nijera Kori, Voluntary Health Services Society (VHSS), BRAC, and Mahila Parishad-formed local-level stakeholder committees with community representatives on an experimental basis.

Despite some small successes in establishing dialogue, the stakeholder committees lacked authority or political clout to enact decisions. An assessment showed that many community members were unaware of the committees and the opportunity they offered to provide feedback about the healthcare system (39). Without strong social or political support from the community and public sector, the majority of stakeholder committees disbanded with minimal impact on public-health service-delivery.

\section{Private for-profit sector action}

Although there are examples of corporations taking advantage of developing countries and marginalized populations, the potential impact of corporate and business actions should not be overlooked as mechanisms for alleviating exclusion. The following are examples of different types of private-sector interventions with potential to impact social exclusion and thus potentially impact health status.

\section{Women's employment in ready-made garment industry (4I)}

Joining the formal labour sector is widely recognized as an important path out of poverty (42). However, it is generally limited for excluded groups because of labour market segmentation (7). The Ready-made Garment (RMG) industry is an exam- 
ple of a sector pulling a targeted excluded groupyoung women generally from low-income rural households-into the formal-sector economy. The remittances RMG workers send home can keep the family from slipping into further poverty and even allow some families to develop skills for better livelihood.

Under the Multi-fibre Arrangement (1974-2004), Bangladesh saw massive growth of the garment industry. Ready-made garments are now the leading national export, accounting for an estimated three-quarters of annual gross domestic product and employing an estimated 2.5 million workers, approximately $80 \%$ of whom are female. When juxtaposed against women's employment in nonexport industries (estimated to be 7\%), the impact that RMG-sector employment is having on women's active participation in the formal economy becomes apparent.

Traditionally, women in Bangladesh have been excluded from formal employment by the cultural constructs of purdah. The rise of garment manufacturing, the decline in the agricultural sector, and high levels of rural poverty have combined to push women to seek work in garment factories. The impact on livelihood of garment workers is mixed. Working conditions are difficult, hours are long, and harassment is common. At the same time, the widespread employment of women in the RMG industry has had a profound impact on the social constructs that limit women's opportunities $(43,44)$. Widespread employment of women in the RMG industry has changed the perception of women from dependents to economic actors who have more say in the direction of their lives $(45,46)$. Compared to other women of the same age, garment workers delay marriage and fertility (47). Finally, women have the opportunity to be employed in the formal sector and earn higher wages than from most other occupations, which provide both an immediate and future economic benefit to the women garment workers, their families and their communities $(43,44)$. The dramatic growth of women in the garment industry has reduced the cultural barrier of purdah and opened up economic, social and political options for a broad class of women and made some progressive social changes more likely.

In addition to the impact the garment industry has had on individual female employees and the perception of women in society, the sometimes strict enforcement of international labour standards and regulations in the garment industry is having an impact within and beyond the garment industry in Bangladesh. In a context in which national employment legislation is weakly enforced, the industry-wide incentive of being competitive in an international market can motivate companies to meet and exceed national legislation. Meeting international standards in the RMG industry can serve to challenge other industries in Bangladesh to also comply with higher standards. In a context in which the state does not tightly enforce labour policies, clearly-articulated and regulated international standards set, enforced, and rewarded by international agencies can motivate the local private sector to meet and exceed the nationally-set basic rights of employees.

Micro-insurance (48)

Access to healthcare is a basic right according to the Bangladesh Constitution. However, in practice, the poor in Bangladesh are largely excluded from public facilities due to lack of money or lack of social connections. It is estimated that out-of-pocket health payments account for as much as $3.8 \%$ of the population falling below the poverty-line of US $\$ 1$ per day annually (49). Poor and rural populations, particularly women, have the most limited access to public-sector health services.

Micro-health insurance (MHI) schemes have been developed to address the lack of access to state-run health clinics $(50,51)$. MHI is a nascent strategy to reduce households entering poverty as a result of a health crisis and broadly increase access to and the use of basic healthcare; it also has the benefits of motivating clients to seek licensed healthcare providers as opposed to care from untrained local providers or self-treatment.

The MHI programmes in Bangladesh promote access to and the use of basic healthcare. While the MHI strategy implemented in Bangladesh regarding the coverage of basic healthcare is beneficial, it does not cover catastrophic care, and healthcare costs still can drive members of MHI schemes deeper into poverty. Examples of expanded MHI in India, on the other hand, aim at improving the quality and reduce the income-impact of secondary and tertiary healthcare. These schemes address high cost, low-frequency events and pose a strategy for addressing the issue of catastrophic health-costs among the poor. 
While access to healthcare should be guaranteed by the state, there are a number of situations in which this is not possible given the existing infrastructure and capacity, with detrimental impact on large portions of the population. In such circumstances, other sectors can supplement public sector services. $\mathrm{MHI}$ is an example of the private sector, or privatesector with NGO partnership, stepping in to supplement inadequate public-sector service-delivery. As currently offered in Bangladesh, MHI inadequately addresses the economic and other barriers that prevent the poor from accessing healthcare. More research is needed to identify whether expanded MHI or other strategies can better serve the needs of the population.

\section{Corporate social responsibility}

Corporate social responsibility (CSR) is another private sector-based strategy with the potential to reduce economic, social, cultural and political exclusion. CSR is an evolving concept globally but, in Bangladesh, it has been defined as a set of business practices based on ethical norms and transparency that contribute to the sustainable development of internal and external stakeholders in the best interest of business society and environment. A sociallyresponsible firm holds a holistic view of itself in relation to its stakeholders and measures its performance via a triple bottom-line: economic/financial, environmental, and social. CSR seeks a path which advances all three measures, none at the cost of the others. Although CSR as a concept may have roots in philanthropic activities, the modern view of CSR is more strategic and complex.

Most strategic CSR programmes share three common characteristics: (a) they are part of the company's core business operations; (b) they use partnerships with NGOs, civil society, or development partners; and (c) they benefit both excluded populations and businesses by matching skills, capabilities, and resources. Three examples of CSR are presented: first, a collaboration between an NGO and two manufacturing firms to address drug-abuse relapse; second, a social business enterprise; and third, the example of Bangladesh's leading pharmaceuticals manufacturers supporting their workers and the local community.

Rehabilitation of drug-addicts: Drug-users in Bangladesh are often discriminated against and have significant difficulty when returning to society after rehabilitation. Typically, more than 90\% of rehabilitated drug-addicts relapse after leaving treatment. A pilot initiative by the NGO-Family Health International-provided skills training and employment for rehabilitated injecting drug-users in private-sector companies and fostered the development of a supportive community. Two manufacturing companies provided job placements. Among project participants, the relapse rate back to drug-use was less than $10 \%$. Most programme participants placed in the factories had high attendance levels and strong job performance. Some participants have been promoted. The pilot initiative shows promise as a strategy to give rehabilitated drug-users the skills and social abilities to build a new life and reduce risk of relapse.

Employment for marginalized women: Hathay Bunano, a Social Business Enterprise, manufactures export-quality handicrafts, toys, and knitwear produced in rural areas. The company actively seeks as employees individuals who are typically excluded from social and economic participation in society, including divorced, illiterate and disabled women.

The Hathay Bunano business model is based on rural production centres. The company finds a group of women in a rural area interested in working and willing to undertake 1-2 month(s) of training. After training, a small production facility is established. Women in the rural centres are given the responsibility to manufacture the knitted items at the required quality level. Since Hathay Bunano's customers are high-end boutiques and retailers in Europe and UK, the quality of the products is critical to the success of the company. This trust by the company greatly empowers women who have previously rarely worked outside the home. Hathay Bunano provides a number of services for its employees, including childcare, a healthcare social worker, and literacy classes. Women with minimal previous social contact benefit from the social networks, economic gains, and cultural change associated with regular women's employment.

Rural development: The Square Group is a large Bangladeshi corporation involved in pharmaceuticals, toiletries, chemicals, and consumer food products for domestic and export markets. Square operates a number of manufacturing facilities in the rural Pabna district of Bangladesh.

Square's investments in rural community development help the company maintain a skilled workforce. Investments in local education include the modern Square Kindergarten which is open to children of employees, management, and the general community. Square provides free pharmaceuticals 
to local public hospitals, sponsors ambulances, and invests in the water and sanitation system by installing improved drainage systems and working to provide safe drinking-water to more of the population. Square works to make the company womenfriendly by giving women preferential access to the company's housing and for women who live in villages, providing transportation to the factories to ensure that women can get to work in a safe environment free from harassment. Square also breaks cultural norms by posting women in non-traditional positions, such as petrol pump attendant. As a result of these practices, Square's workforce comprises around $26 \%$ of women. The employee turnover rate for women is almost zero.

These three examples of strategic CSR show diversity in CSR strategies driven by different organizational capabilities and resources. Corporations can be socially responsible by changing their business strategies. As CSR need not cut into financial profits, the strategy is theoretically applicable regardless of the economic environment.

\section{DISCUSSION}

This application of social exclusion theory to assess multiple policies and actions that have the potential to reduce exclusion in Bangladesh suggests that the social exclusion framework put forth by the Social Exclusion Knowledge Network is a helpful tool for policy analysis in Bangladesh. Three key findings emerge from this presentation of multiple policies and actions that have the potential to alter the processes that create conditions of exclusion. First, the case studies support that a number of actors, including the state, civil society, the NGO sector, the private sector, and international agencies, can impact the processes that contribute to social exclusion or cohesion. Second, while financial poverty is an important contributor to social exclusion in Bangladesh, cultural, political and social exclusion also impact development of people's capabilities and their access to society's resources. Third, there is a dearth of data on exclusion, exclusionary processes, and the link between exclusionary processes and health inequities; this needs to be rectified.

\section{Multiple actors address exclusion}

The Bangladesh Constitution mandates that "[I] $t$ shall be a fundamental responsibility of the state to attain, through planned economic growth, a constant increase of productive forces and a steady improvement in the material and cultural standard of living of the people, with a view to securing to its citizens the provision of the basic necessities of life, including food, clothing, shelter, education and medical care ..." (53).

While the state has the responsibility of implementing and enforcing policies to reduce exclusion, a number of actors, including the state, civil society, the NGO sector, the private sector, including the international corporate sector, and multilateral agencies, can impact the processes that contribute to social exclusion or cohesion. The state has the lead responsibility to implement and enforce policies to reduce exclusion, to develop, implement, and systematically monitor the long-term strategies that aim to encourage social cohesion, and also to support documentation of the relationships between social exclusion and health. The state has the responsibility of coordinating and monitoring the long-term strategy of the activities of the coalition of actors, including public and private-sectors, civil society, and other institutions and organizations that have the potential to address the processes contributing to social exclusion.

However, in Bangladesh, as in a number of other countries, the public sector is not able to provide basic services to much of the population or sufficiently regulate other sectors to ensure social responsibility. As a result-as shown in the case studies presented-other sectors, particularly NGOs, including religious organizations, play an important role in delivering services, such as education and healthcare. While these NGOs provide key services for those who would otherwise not have them, NGOs are not necessarily able to provide consistent services across time and space, and quality assurance is difficult to guarantee. When NGOs become partners with the state in providing basic services, they lose their independence and their ability to play the important civil society role of holding the government accountable to a high level of service-delivery for the general public (40).

Employment policies of private for-profit companies can promote social inclusion by targeting groups facing discrimination, including women and people with disabilities $(41,52)$. Job-skills training and subsequent employment have important roles to play in promoting social inclusion. In addition to adhering to the principles of strategic corporate sector responsibility, some private-sector companies promote better labour practices within the country simply by complying with international labour standards required to compete for international contracts. More regular compliance with 
international standards in the garment sector in Bangladesh, for example, has motivated demands for improved labour practices in other sectors. Improved compliance to increase competitiveness in the international market is an important strategy and may be a precursor to but not a substitute for sound national labour policy and enforced state regulations (52).

International agencies, such as donors and United Nations agencies, play important roles in working with different sectors to support adherence to legislation on international rights and to promote policies and actions that aim at reducing social exclusion. In addition, international agencies have a role of supporting the state in coordinating and monitoring the long-term strategy of the public and private-sectors, civil society and activities of other institutions and organizations that have the potential to address the processes contributing to social exclusion.

\section{Multidimensional policies and actions are necessary to address exclusion}

While financial poverty is an important contributor to social exclusion in Bangladesh, cultural, political and social factors also impact development of peoples' capabilities and their access to society's resources. The examples in the case studies made clear that policies and actions that address deprivation and exclusion need to go beyond being 'pro-poor', beyond providing short-term financial incentives to address the multiple dimensions of exclusion and the related deficiencies in capabilities and resources that result in marginalization and deprivation.

The contrast in terms of impact on women's participation in society between the Female Secondary School Stipend Program (FSP) and employment in the ready-made garment (RMG) industry suggests that short-term financial incentives are inefficient means of creating social change compared to demonstrating a demand for enhanced capabilities. A consistent goal of the FSP has been to delay marriage and childbirth among girls and young women. The FSP provides short-term financial incentives to encourage parents to send unmarried daughters to school. However, after 14 years of implementation throughout rural Bangladesh, there is no evidence that the FSP is contributing to a delay in marriage or delayed fertility. Critics have charged that the FSP encourages parents to send daughters to school for the stipend rather than to increase the capabilities outside traditional roles of girls.
In contrast, by giving better opportunities to women with higher levels of education, the RMG industry has been associated with motivating families to educate their daughters to increase their economic capabilities. In addition, participation in the RMG workforce has motivated delayed marriage and delayed fertility for young female workers. This is not meant to belittle the challenges and hazards associated with working in the RMG industry, rather to note the contrast of the natural experiment of the RMG industry to that of the FSP. The RMG industry capitalizes on the economic capabilities of young women, provides an obvious incentive for females to pursue education, delay marriage and childbirth, thereby altering the cultural and social conditions that prescribe early marriage and fertility.

Viewing the FSP through the lens of social exclusion theory suggests that the programme insufficiently addresses cultural and social barriers that can make school participation difficult for adolescent girls and insufficiently enhances the capabilities of girls beyond bringing in a monthly stipend during the period in which they meet the conditions of FSP.

The group-based microcredit programmes more specifically address dimensions of exclusion. Credit and skills development address economic resources and capabilities; participation in group meetings outside the household creates new social networks and increases women's mobility, building social and cultural resources and capabilities. However, these programmes are not designed with the explicit intent of mitigating specific dimensions of exclusion and the programmes have not been formally evaluated in this way. Giving increased attention to the different dimensions of exclusion may yield the development of richer and more responsive policies and actions to address the specific dimensions of exclusion and facilitate more in-depth and informative analyses.

\section{More evidence is required}

Critically, the dearth of data on exclusion, exclusionary processes, and the link between exclusionary processes and health inequities needs to be rectified. This analysis makes clear the need for strengthened evidence that identifies the processes that contribute to exclusion and cohesion and that demonstrate the relationships between social exclusion and health equity. There is a need to develop measureable indicators for social, political, economic and cultural capabilities and resources; to measure changes in degrees of social exclusion associated with different actions and interventions; 
and to measure changes in health status associated with different levels of social exclusion. To generate documentation of relationships between social exclusion and health, social scientists need to be increasingly engaged in the design, implementation, monitoring, and evaluation of interventions and processes-from multiple sectors-that are meant to or have the potential to enhance individual or community capabilities and resources, thereby altering relationships between these individuals and communities and the larger structures of society and, in turn, perhaps impacting health equity.

Health is an essential component of individual and societal livelihood. While the negative relationships between deprivation and health have been demonstrated, relatively few studies have explored relationships between the structural processes that contribute to deprivation and health status. Health is not a dimension typically included in social exclusion analysis. In reviewing interventions and actions that are meant to or have the potential to change the relationships between people and the social, economic, political and cultural structures that shape society, this analysis finds that health status is too often tangential.

The impact of actions and interventions meant to enhance capabilities and resources, and the impact of changed capabilities and resources on health often go unmeasured. For example, the Hathay Bunano project works with marginalized women to develop new income-generating skills. The company brings women together giving them a social network; women receive salaries, enhancing their economic resources. However, the impact of joining Hathay Bunano on employees' social, economic, political and cultural capabilities and resources is unmeasured, as is the health impact of engaging in private-sector employment, having a regular income and strengthened social network and other associated gains in resources. Similarly, micro-insurance interventions have increased the abilities of clients to access and use formal healthcare services; however, the intermediary factors have not been measured, and assessments of the health impact of participating in micro-insurance programmes in Bangladesh could not be found.

There are a few exceptions. Numerous studies, including Ahmed's analysis of targeting the ultrapoor (28) and Schurmann and Johnston's study of microcredit (19) both published in this issue of the Journal, have explored the impact of participation in microcredit programmes on social, human and financial capital. Mohindra and Haddad (54) and
Schurmann and Johnston begin to disentangle the processes through which different social, political, economic and cultural forces associated with participation in a microcredit programme operate to influence health expectations and functioning (19). The challenge remains to measure the variables and the strength of their relationship with health.

\section{CONCLUSION}

The right to the conditions necessary to achieve the highest attainable standard of health is universal as stated in the Universal Declaration of $\mathrm{Hu}$ man Rights (55). The Constitution of Bangladesh recognizes the responsibility of the state to provide essential services to enable Bangladeshi citizens to enjoy a basic standard of living.

With continued population growth, increased landlessness, fewer agricultural opportunities, and rapid urbanization, the inequalities evident in modern Bangladesh society are predicted to grow and translate into increased health inequity. There is an urgent need to identify and promote processes that can reduce social exclusion. This paper has identified several policies, actions, and players in addition to the state that have potential to reduce exclusion. However, for most policies and actions, adequate data are not available to provide evidence of impact on changes in levels of exclusion or on health status.

In this context, the assessments upon which this paper is based demonstrate the need for the development and implementation of indicators that can be used in measuring degrees of social, economic, political and cultural exclusion; implementation of a system of measuring the impact of policies and actions that have the potential to mitigate exclusionary processes; systematic measurement of relationships between exclusion and health status; and promotion of processes that reduce exclusion and improve health equity. These actions will support evidence-based planning to address societal and health inequities. Ideally, such actions would re-invigorate the concepts of social inclusion and health equity as essential elements of good governance in Bangladesh.

\section{ACKNOWLEDGEMENTS}

This work was made possible through funding provided by the World Health Organization (WHO) through Lancaster University and undertaken as work for the Social Exclusion Knowledge Network established as part of the WHO Commission on 
the Social Determinants of Health. The views presented in this report are those of the author and do not necessarily represent the decisions, policy, or views of WHO or Commissioners.

The paper has benefited greatly from the input of many people. They include: Syed Masud Ahmed, Abbas Bhuiya, Sarah Escorel, Mario Hernandez Alveraz, Nidhi Khosla, Simeen Mahmud, Jennie Popay, Sabina Faiz Rashid, Laetitia Rispel, Anna Schurmann, and Wendy Werner.

\section{REFERENCES}

1. de Haan A. Bibliographic review on social exclusion in South Asia. Chapter 1. In: de Haan A, Nayak P, editors. Social exclusion and South Asia: a regional bibliographical review; the case of India. Geneva: International Institute for Labour Studies, 1995. (http://www.ilo.org/public/english/bureau/inst/ papers/1994/dp77/ch1.htm, accessed on 15 January 2007).

2. Bhalla A, Lapeyre F. Social exclusion: toward an analytical and operational framework. Dev Change 1997;28:413-33.

3. World Bank. Gender, social inclusion, and rural infrastructure services: final report. Washington, DC: World Bank, 2002. 9 p.

4. Hooper E. Review of social exclusion in selected countries in DFID Asia Region. London: Department for International Development, 2003. 2 p.

5. Beall J, Piron L-H. DFID social exclusion review. London: London School of Economics, 2005. 71 p.

6. Hobcraft J. Child development, the life course, and social exclusion: are the frameworks used in the UK relevant for developing countries? Manchester: Chronic Poverty Research Centre, University of Manchester, 2007:1-12. (Chronic Poverty Research Centre working paper no. 72).

7. Kabeer N. Social exclusion and the MDGs: the challenge of 'durable inequalities' in the Asian context. In: Asia 2015 Conference: Promoting Growth, Ending Poverty, March 2006, Overseas Development Institute, Brighton. London: Institute of Development Studies, 2006. $30 \mathrm{p}$.

8. Rahman A, Razzaque A. On reaching the hardcore poor: some evidence on social exclusion in NGO programmes. Bangladesh Dev Stud 2000;26:1-35.

9. Saith R. Social exclusion: the concept and application to developing countries. Oxford: University of Oxford, 2001. 17 p. (Queen Elizabeth House working paper no. 72).

10. World Health Organization. Macroeconomics and health: investing in health for economic develop- ment: report of the Commission on Macroeconomics and Health. Geneva: World Health Organization, 2001. $210 \mathrm{p}$.

11. Meesen B, Zhang Z, Van Damme W, Devadasan N, Criel B. Iatrogenic poverty (editorial). Trop Med Int Health 2003;8:581-4.

12. Xu K, Evans DB, Kawabata K, Zeramdini R, Klavus J, Murray CJ. Household catastrophic health expenditure: a multicountry analysis. Lancet 2003;362:111-7.

13. Sen B. Drivers of escape and descent: changing household fortunes in rural Bangladesh. World Dev 2003;31:513-34.

14. Popay J, Escorel S, Hernández M, Johnston H, Mathieson J, Rispel L. Understanding and tackling social exclusion: final report to the WHO Commission on Social Determinants of Health from the Social Exclusion Knowledge Network. Geneva: World Health Organization, 2008. 207 p. (http://www.who.int/ social_determinants/knowledge_networks/final_reports/sekn_final\%20report_042008.pdf, accessed on 8 May 2008).

15. World Bank. Social safety nets in Bangladesh: an assessment. Dhaka: World Bank Office, 2006. 54 p. (Bangladesh development series paper no. 9). (http:// siteresources.worldbank.org/BANGLADESHEXTN/ Resources/ FINAL-printversion_PAPER_9.pdf, accessed 23 December 2008).

16. Schurmann A. Review of the Bangladesh Female Secondary School Stipend Project using a social exclusion framework. J Health Popul Nutr 2009;27:515-17.

17. Streatfield PK, Karar ZA. Population challenges for Bangladesh in the coming decades. J Health Popul Nutr 2008;26:261-72.

18. Ahmed SS. Delivery mechanisms of cash transfer programmes to the poor in Bangladesh. In: Third International Conference on Conditional Cash Transfers, Istanbul, Turkey, June 26-30, 2006. Washington, DC: World Bank, 2005. 86 p. (Social protection discussion paper series no. 0520).

19. Schurmann A, Johnston HB. The group-lending model and social closure: microcredit, exclusion, and health in Bangladesh. J Health Popul Nutr 2009;27:518-27.

20. Kabeer N. Snakes, ladders and traps: changing lives and livelihoods in rural Bangladesh (1994-2001). Manchester: Chronic Poverty Research Centre, University of Manchester, 2004. 53 p. (Chronic Poverty Research Centre working paper no. 50).

21. Pitt MM, Khandker SR, Chowdhury OH, Millimet DL. Credit programs for the poor and the health status of children in rural Bangladesh. Int Econ Rev 2003;44:87118. 
22. Khandker SR. Microfinance and poverty: evidence using panel data from Bangladesh. World Bank Econ Rev 2005;19:263-86.

23. Amin R, St. Pierre M, Ahmed A, Haq R. Integration of an essential services package (ESP) in child and reproductive health and family planning with a micro-credit program for poor women: experience from a pilot project in rural Bangladesh. World Dev 2001;29:1611-21.

24. Levin A, Rahman MA, Quayyum Z, Routh S, Barkat-e-Khuda. The demand for child curative care in two rural thanas of Bangladesh: effect of income and women's employment. Int J Health Plann Manage 2001;16:179-94.

25. Amin R, Ahmed AU, Chowdhury J, Ahmed M. Poor women's participation in income-generating projects and their fertility regulation in rural Bangladesh: evidence from a recent survey. World Dev 1994;22:55565.

26. Schuler SR, Hashemi SM. Credit programs, women's empowerment, and contraceptive use in rural Bangladesh. Stud Fam Plann 1994;25:65-76.

27. Halder SR, Mosley P. Working with the ultra-poor: learning from BRAC experiences. I Int Dev 2004; 16:387-406.

28. Ahmed SM. Capability development among the ultra-poor in Bangladesh: a case study. J Health Popul Nutr 2009;27:528-35.

29. Bangladesh Bureau of Statistics. Preliminary report of the household income and expenditure survey 2005. Dhaka: Bangladesh Bureau of Statistics, 2006. 94 p.

30. Matin I, Halder SR. Combining methodologies for better targeting of the extreme poor: lessons from BRAC's CFPR/TUP programme. Dhaka: Bangladesh Rural Advancement Committee, 2004. 23 p. (CFPR/ TUP working paper series no. 2).

31. Sen B, Hulme D. Chronic poverty in Bangladesh: tales of ascent, descent, marginality, and persistence (draft). In: The state of the poorest 2004/2005. Dhaka: Bangladesh Institute of Development Studies, 2004. $199 \mathrm{p}$.

32. Sulaiman M, Matin I, Siddiquee M, Barua P, Alarakhaia S, Iye, V. Microfinance engagements of the 'graduated' TUP members. Dhaka: Bangladesh Rural Advancement Committee, 2006. 25 p. (CFPR/TUP working paper series no. 9).

33. Rabbani M, Prakash VA, Sulaiman M. Impact assessment of CFPR/TUP: a descriptive analysis based on 2002-2005 panel data. Dhaka: Bangladesh Rural Advancement Committee, 2006. 35 p. (CFPR/TUP working paper series no. 12).

34. Rashid SF. Strategies to reduce exclusion among populations living in urban slum settlements in Bangladesh. J Health Popul Nutr 2009;27:574-86.
35. Rashid SF, Hossain Y. Constraints in delivering services to the urban poor living in slums in Dhaka, Bangladesh. Washington, DC: World Bank, 2005:1-60.

36. World Bank. Dhaka: improving living conditions for the urban poor. Dhaka: World Bank Office, 2007. 158 p. (World Bank report no. 35824-BD).

37. Ahmed R. DSK: a model for securing access to water for the urban poor. London: WaterAid, 2003. 6 p. (WaterAid field work report). (http://docs.watsan. net/Downloaded_Files/PDF/Ahmed-2003-DSK.pdf, accessed on 7 August 2008).

38. Gwatkin D, Bhuiya A, Victora C. Making health systems more equitable. Lancet 2006;364:1273-80.

39. Mahmud S. Citizen participation in the health sector in rural Bangladesh: perceptions and reality. IDS Bull 2004;35(2):11-8.

40. Schurmann A, Mahmud S. Civil society, health, and social exclusion in Bangladesh. J Health Popul Nutr 2009;27:536-44.

41. Khosla N. The ready-made garment industry in Bangladesh: a pathway to social cohesion? Dhaka: Southeast Asia Hub of the Social Exclusion Knowledge Network, International Centre for Diarrhoeal Disease Research, Bangladesh, 2008. 15 p. (WHO Social Exclusion Knowledge Network background paper no. 21).

42. Karnani A. Microfinance misses its mark. Stanford Soc Innovation Rev 2007;(Summer):34-40.

43. Ahmed SS, Bould S. One daughter is worth 10 illiterate sons: reframing the patriarchal family. J Marriage Fam 2004;66:1332-41.

44. Kabeer N, Mahmud S. Rags, riches and women workers: export-oriented garment manufacturing in Bangladesh. In: Carr M, editor. Chains of fortune: linking women producers and workers with global markets. London: Commonwealth Secretariat, 2004:133-62.

45. Amin S, Diamond I, Naved RT, Newby M. Transition to adulthood of female garment-factory workers in Bangladesh. Stud Fam Plann 1998;29:185-200.

46. Rashid SF. Emerging changes in reproductive behaviour among married adolescent girls in an urban slum in Dhaka, Bangladesh. Reprod Health Matters 2006;14:151-9.

47. Meyers C. Adolescent girls' livelihoods. Essential questions, essential tools: a report on a workshop. New York, NY: Population Council, 2000. 54 p.

48. Werner W. Micro-insurance in Bangladesh: risk protection for the poor? J Health Popul Nutr 2009;27:56373.

49. van Doorslaer E, O'Donnell O, Rannan-Eliya RP, Somanathan A, Adhikari SR, Garg CC et al. Cata- 
strophic payments for healthcare in Asia. Health Econ 2007;16:1159-84

50. Uddin MF. Micro health insurance: profile of community based schemes in Bangladesh. Dhaka: Women's Empowerment through Employment and Health Project, International Labour Organization, 2003. 42 p.

51. International Labour Organization. Micro insurers: inventory of micro insurance schemes in Bangladesh. Dhaka: Women's Empowerment through Employment and Health Project, International Labour Organization, 2003. 57 p.

52. Werner W. Corporate social responsibility initiatives addressing social exclusion in Bangladesh. J Health Popul Nutr 2009;27:545-62.
53. Bangladesh, Government of. The Constitution of Bangladesh. Part II, Section 15(a). (http://www. pmo.gov.bd/constitution/, accessed on 15 September 2008)

54. Mohindra K, Haddad S. Women's interlaced freedoms: a framework linking microcredit participation and health. J Hum Dev 2005;6:353-74.

55. United Nations. Universal declaration of human rights: adopted and proclaimed by UN General Assembly Resolution 217 A (III) of 10 December 1948. New York, NY: United Nations, 1948. 5 p. (http:// www.unponteper.it/liberatelapace/dossier/UN/ass_ gen_un_dich_un_dir_um.pdf, accessed on 15 September 2008). 